\title{
Using Quantitative Fractography to Determinine the Influence of Carbides on Crack Path in a Directionally Solidified Superalloy
}

\author{
M.D. Trexler* and T.H. Sanders* \\ * Department of Materials Science and Engineering, Georgia Institute of Technology, Atlanta, GA \\ 30332-0245
}

Directionally solidified superalloys are commonly used in land based turbines because of increased high temperature strength over conventional alloys due to a reduction of grain boundaries that are perpendicular to the loading axis [1]. To understand how microstructure affects mechanical properties, detailed characterization was made using optical and electron microscopy on bulk specimens as well as on post-mortem tensile fracture surfaces. Characterization included quantitative determination of features such as the volume fraction of metallic carbides (MC) and relating the results to the carbide's role on the fracture process.

The microstructure of this alloy consists of a strengthening precipitate phase $\gamma^{\prime}$ and $\mathrm{MC}$ carbides in a matrix of $\gamma$. The carbides were chosen for further investigation based on the observation that they can be found in abundance on the fracture surfaces. The carbides form during casting and have very irregular morphologies that are commonly referred to as "Chinese script" morphology. Energy dispersion spectroscopy (EDS) determined the carbides to be rich in Ta and Ti (FIG 1). The bulk volume fractions of $(\mathrm{Ta}, \mathrm{Ti}) \mathrm{C}$ carbides were determined to be $2.0 \%$ using a point counting stereology method.

Tensile specimens tested at temperatures ranging from $25^{\circ} \mathrm{C}-870^{\circ} \mathrm{C}\left(77^{\circ} \mathrm{F}-1600^{\circ} \mathrm{F}\right)$ were selected for quantitative analysis to determine the effect of MC morphology on the crack path during failure [2]. Backscattered Electron (BSE) imaging was employed to separate the Ta-rich carbides from the matrix using compositional contrast [3]. A qualitative comparison between bulk samples and fracture surfaces is made in FIG 2. It is clear that the area fraction of carbides in the bulk is less than the area fraction on the fracture surfaces suggesting that the crack path tends to prefer areas rich in the carbide phase.

Measurements made to quantify the area fraction of carbides on the fracture surface must correct for the fact that SEM images are 2-D projections of 3-D objects [4]. The area fraction of the 2-D projection is considered the apparent area fraction, $A_{\text {carbides }}$. To calculate roughness parameter, $R_{s}$ profilemetry was employed by sectioning the fracture surfaces along a plane perpendicular to the tensile axis such that $R_{s}=R_{l} \cdot \varphi$ [4]. $R_{l}$ is the total length of the profile (FIG 3.) divided by the projected length and $\varphi$ is a structure factor. The corrected area fraction of carbides, $F_{\text {carbides }}$ on the surface can be given by [4]:

$$
F_{\text {carbides }}=\frac{R_{s}}{\left(R_{s}\right)_{\text {carbides }}} \cdot A_{\text {carbides }}
$$

where $A_{\text {carbides }}$ is the apparent area fraction of the carbides from the SEM fractograph and $\left(R_{s}\right)_{\text {carbides }}$ is the roughness parameter of the carbide phase. Results determined that $F_{\text {carbides }} \sim 6.0 \%$, which quantitatively shows that cracks tend to follow carbide enriched paths. 
References

[1] H Chester Sims. Superalloys II. John Wiley and Sons, 1987.

[2] J.I. Goldstein et al., Scanning Electron Microscopy and X-ray Microanalysis, Plenum, New York, 1992.

[3] Ibanez. PhD thesis, Georgia Institute of Technology, 2003

[4] Arun M. Gokhale. AMS Handbook, 11 (2002) 538.

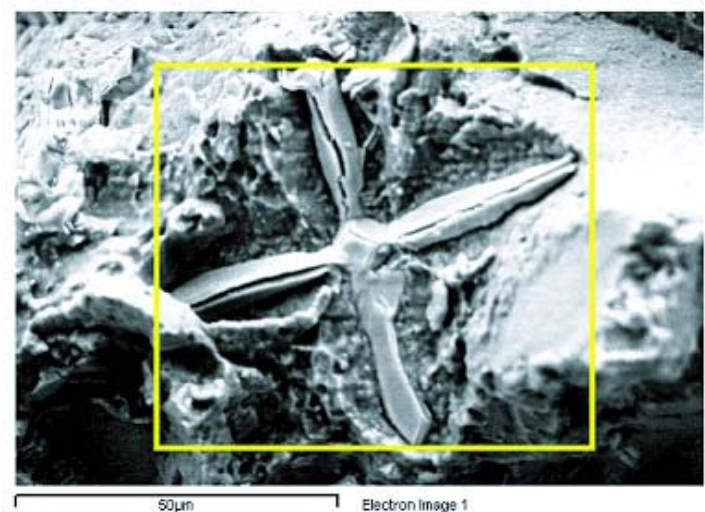

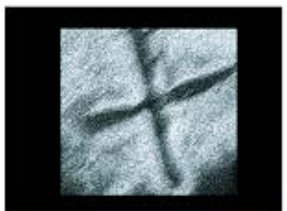

Nickel

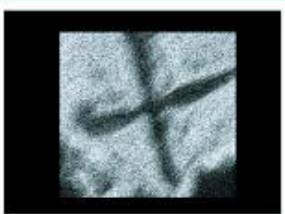

Chromium

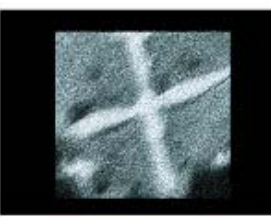

Titanium

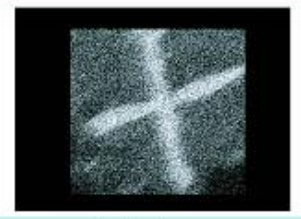

Tantalum

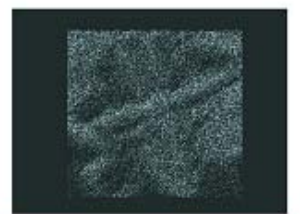

Carbon

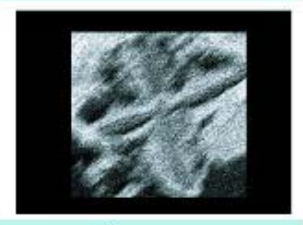

Oxygen

FIG. 1. X-ray map of "script" carbide on tensile fracture surface. Test temperature was $760^{\circ} \mathrm{C}$ $\left(1400^{\circ} \mathrm{F}\right)$.
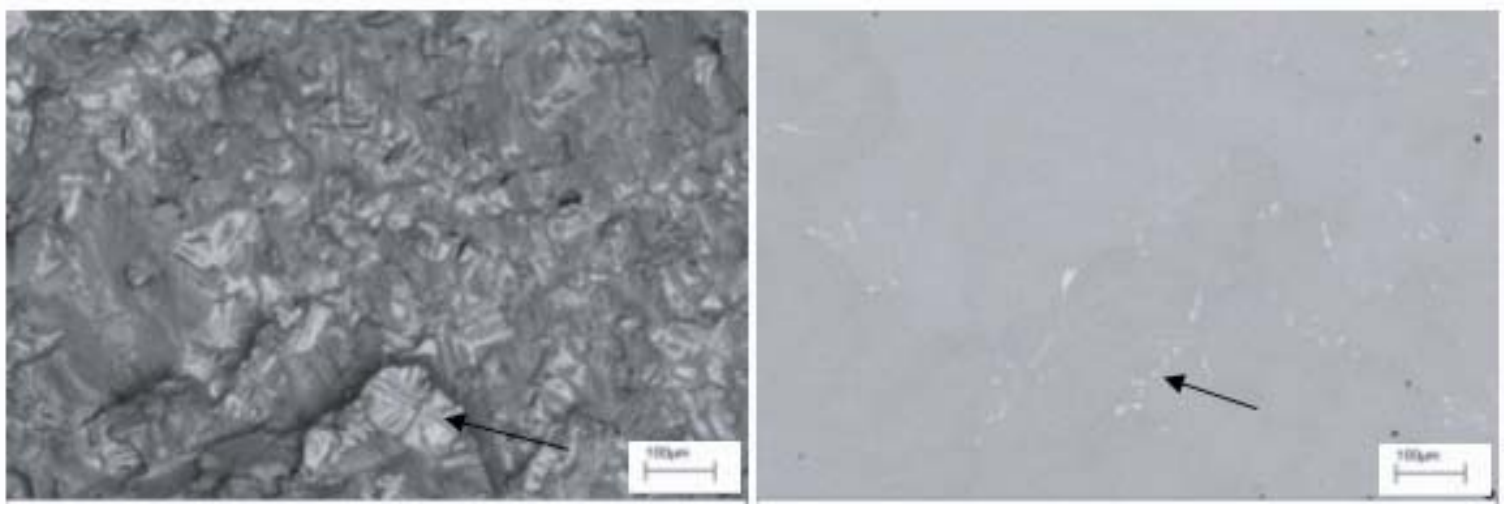

FIG. 2. BSE images of a fracture surface (left) and plane beneath fracture (right). The arrows point to carbides. The test temperature was $650^{\circ} \mathrm{C}\left(1200^{\circ} \mathrm{F}\right)$. Scale bar $=100 \mu \mathrm{m}$.

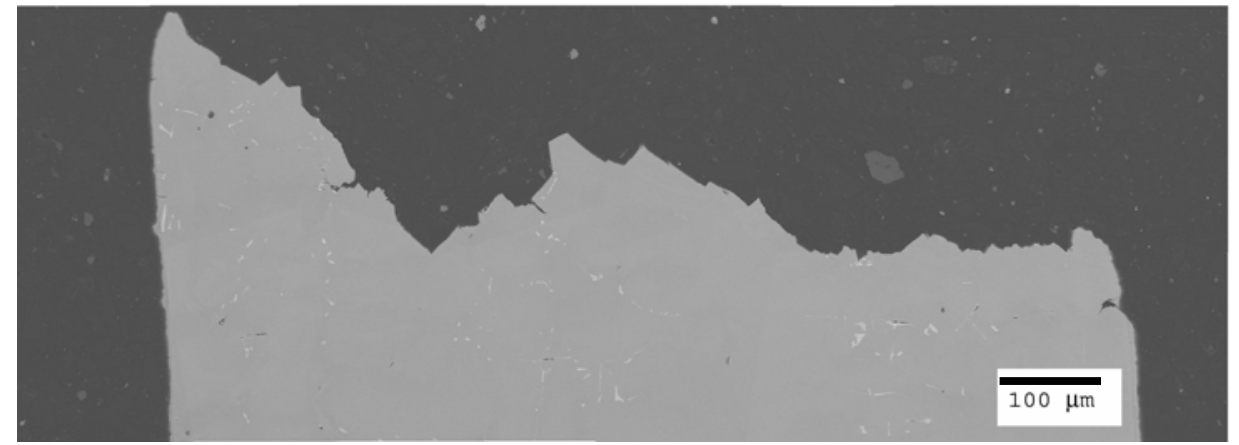

FIG. 3. BSE image of a test specimen profile. The test temperature was $650^{\circ} \mathrm{C}\left(1200^{\circ} \mathrm{F}\right)$. 